\title{
Vancomycin-resistant Gram-positive bacterial endophthalmitis: epidemiology, treatment options, and outcomes
}

\author{
Manav Khera ${ }^{1}$, Avinash Pathengay ${ }^{1 *}$, Animesh Jindal ${ }^{1}$, Subhadra Jalali², Annie Mathai ${ }^{2}$, Rajeev Reddy Pappuru ${ }^{2}$, \\ Nidhi Relhan², Taraprasad Das ${ }^{3}$, Savitri Sharma ${ }^{3}$ and Harry W Flynn $\mathrm{Jr}^{4}$
}

\begin{abstract}
Background: The purpose of this study is to evaluate the microbiological profile and treatment outcomes of vancomycin-resistant Gram-positive bacterial endophthalmitis. Medical records of all patients with Gram-positive bacterial endophthalmitis resistant to vancomycin presenting between 1 January 2005 and 31 December 2010 were reviewed in this noncomparative, consecutive, retrospective case series. Favorable outcome was defined as a best-corrected visual acuity of $\geq 20 / 200$.

Results: Out of 682 culture-positive endophthalmitis isolates, 448/682 (65.6\%) were associated with Gram-positive bacteria. In vitro resistance to vancomycin was noted in $7 / 448$ (1.56\%). Three cases were posttraumatic, three were postoperative, and one was endogenous in origin. Four Bacillus isolates, two Staphylococcus isolates, and an Enterococcus isolate were resistant. Isolates resistant to vancomycin were sensitive in vitro to ciprofloxacin in 6/7 (86\%) patients. Presenting visual acuity was light perception in all seven cases. Favorable outcome was achieved in only $1 / 7(14.3 \%)$ cases.

Conclusions: Vancomycin-resistant endophthalmitis is uncommon and usually associated with poor visual outcome. Bacillus sp. is the most frequent Gram-positive bacteria resistant to vancomycin. Fluoroquinolones like ciprofloxacin may be considered as a useful alternative in vancomycin-resistant endophthalmitis.
\end{abstract}

Keywords: Antibiotics, Antibiotic resistance, Endophthalmitis, Gram-positive organisms, Vancomycin, Vitrectomy

\section{Background}

Management of endophthalmitis includes performing either vitreous tap/biopsy or vitrectomy and institution of appropriate intravitreal antibiotic therapy. Gram-positive bacteria are the most common cause of both exogenous and endogenous endophthalmitis. Vancomycin is considered to be the drug of choice for empiric coverage of Gram-positive organisms in endophthalmitis. However, there are few reports of vancomycin resistance in Gram-positive bacterial isolates (Enterococcus sp. and Staphylococcus sp.) associated with endophthalmitis $[1,2]$. The current study evaluates microbiological characteristics and visual outcome of vancomycin-resistant Gram-positive bacterial endophthalmitis in a large clinical series.

\footnotetext{
* Correspondence: avinash@lvpei.org

'LV Prasad Eye Institute, GMR Varalakshmi Campus, Visakhapatnam 530040, India Full list of author information is available at the end of the article
}

\section{Methods}

In this noncomparative, consecutive case series, the medical records of all patients with culture-proven, clinically diagnosed, infective bacterial endophthalmitis between January 2005 and December 2010 were reviewed after obtaining institutional review board approval. The study followed the Declaration of Helsinki guidelines. Data collected included demographic details, etiology, complications of surgery, duration of symptoms, interval between the event and presentation to the institute, use of medication (topical or systemic), examination findings (presenting visual acuity, presence of hypopyon, presence of vitreous cells, and optic disk visibility), ultrasonography (with attention to the presence of vitreous membranes), and microbiology (including culture and sensitivity). The Endophthalmitis Vitrectomy Study recommendations [3] (vitrectomy reserved for eyes with 
presenting vision of light perception and vitreous biopsy for eyes with presenting vision of hand motions at $1 \mathrm{~m}$ or more) were followed in postoperative endophthalmitis eyes only. Vitrectomy was performed in all eyes with traumatic and endogenous endophthalmitis. All eyes received intravitreal vancomycin $(1.0 \mathrm{mg}$ in $0.1 \mathrm{ml})$ and amikacin $(0.4 \mathrm{mg}$ in $0.1 \mathrm{ml})$ or ceftazidime $(2.25 \mathrm{mg}$ in $0.1 \mathrm{ml})$. Treatment and management decisions were made by the individual treating physicians without a predefined study protocol. The undiluted vitreous biopsy samples were stained with Gram stain for microscopy and also inoculated directly onto 5\% sheep blood agar, chocolate agar, Sabouraud dextrose agar, thioglycollate, and brain-heart infusion broth. A culture was considered positive when there was growth of the same organism on two or more media, confluent growth at the site of inoculation on one solid medium, or growth in one medium with consistent microscopy findings. Antibiotic sensitivity was tested by disk diffusion technique. A best-corrected visual acuity of 20/200 or more at final follow-up was defined as a favorable outcome.

\section{Results}

Of 682 culture-positive endophthalmitis, 448 (65.6\%) were associated with Gram-positive bacteria. Resistance to vancomycin was noted in $7(1.56 \%)$ cases. Mean age of the patients was 35 years (range 4 to 70 years). Three cases were posttraumatic, three were postoperative, and one was endogenous in origin. All cases, except the one with endogenous endophthalmitis, presented within 1 week of symptoms. Presenting visual acuity was only light perception in all seven cases. The details of the primary and secondary interventions are summarized in Table 1. Vancomycin resistance was commonly noted in Bacillus sp. (4 of 96, 4.17\%), followed by Staphylococcus sp. (2 of 80, 2.5\%) and Enterococcus sp. (1 of 5, 20\%). Six of the seven isolates also had multidrug resistance. Six $(86 \%)$ isolates were sensitive to ciprofloxacin followed by 4 (57\%) each to gentamicin, gatifloxacin, and ceftazidime (Table 2). Favorable outcome was achieved in $1 / 7$ $(14.3 \%)$ patients. Five eyes went into phthisis, while one patient achieved counting fingers at $1 \mathrm{~m}$.

\section{Discussion}

Vancomycin is a widely used glycopeptide antibiotic that is effective against most Gram-positive bacteria including Streptococcus, Staphylococcus, and Bacillus species. It is commonly used for the treatment of methicillin-resistant coagulase-negative Staphylococcus and methicillin-resistant Staphylococcus aureus (MRSA) infections. Vancomycin kills bacteria by binding irreversibly to D-alanyl-D-alanine moieties of the $\mathrm{N}$-acetylmuramic acid (NAM) and $N$ acetylglucosamine (NAG) peptides. This inhibits the synthesis and cross-linking of the NAM/NAG polymers that form the backbone of the cell wall. Resistant mutants are very rare, except for vancomycin-resistant Enterococcus. The mechanism of acquiring vancomycin resistance includes conversion of D-Ala-D-Ala to the depsipeptide D-Ala-D-Lac or to D-Ala-D-Ser, leading to altered cross-linkages in the peptidoglycans of the cell wall [4].

In the Endophthalmitis Vitrectomy Study, 100\% of the Gram-positive bacteria were susceptible to vancomycin [5]. However, in the current series, three acute-onset postoperative endophthalmitis patients with Grampositive organisms (Staphylococcus epidermidis, Bacillus sp., and Enterococcus faecalis) were resistant to vancomycin. There have been reports of using vancomycin as a prophylaxis either intracamerally or in the irrigating solution during cataract surgery [6,7] which may possibly increase the emergence of vancomycin-resistant

Table 1 Demographic characteristics, etiology, management, and outcomes of patients with vancomycin-resistant endophthalmitis due to Gram-positive bacteria

\begin{tabular}{|c|c|c|c|c|c|c|c|c|c|c|c|c|c|c|}
\hline $\begin{array}{l}\text { Serial } \\
\text { number }\end{array}$ & $\begin{array}{c}\text { Age } \\
\text { (years) }\end{array}$ & Sex & Etiology & $\begin{array}{c}\text { Duration } \\
\text { (days) }\end{array}$ & $\begin{array}{c}\text { Presenting } \\
\text { V/A }\end{array}$ & $\begin{array}{c}\text { Primary } \\
\text { intervention }\end{array}$ & $\begin{array}{c}\text { Secondary } \\
\text { intervention }\end{array}$ & Smear & $\begin{array}{c}\text { Systemic } \\
\text { antibiotic }\end{array}$ & $\begin{array}{c}\text { Intravitreal } \\
\text { antibiotic }\end{array}$ & $\begin{array}{l}\text { Intravitreal } \\
\text { steroid }\end{array}$ & $\begin{array}{l}\text { Final } \\
\text { V/A }\end{array}$ & $\begin{array}{c}\text { Follow- } \\
\text { up } \\
\text { (months) }\end{array}$ & Outcome \\
\hline 1 & 20 & M & Trauma & 1 & $L P$ & $\begin{array}{c}C T R+P P V \\
+I O A B\end{array}$ & $\begin{array}{l}P P V+M \\
+C+T\end{array}$ & GPB & Ciprofloxacin & $V+C$ & $\mathrm{~T}$ & $C F-1 m$ & 3 & Unfavorable \\
\hline 2 & 70 & $\mathrm{~F}$ & $\begin{array}{c}\text { Postcataract } \\
\text { surgery }\end{array}$ & 5 & $L P$ & $\begin{array}{l}\text { PPV + IOAB + } \\
\text { IOL explant }\end{array}$ & Nil & GPC & Gatifloxacin & $V+A$ & D & $L P$ & 3 & Unfavorable \\
\hline 3 & 70 & M & $\begin{array}{c}\text { Postcataract } \\
\text { surgery }\end{array}$ & 1 & $L P$ & $P P V+I O A B$ & $C+T$ & GPB & Ciprofloxacin & $V+A$ & $\mathrm{~T}$ & $20 / 20 p$ & 4 & Favorable \\
\hline 4 & 5 & M & Trauma & 1 & $L P$ & $\begin{array}{l}C T R+P P L+ \\
P P V+I O A B\end{array}$ & Nil & GPB & Cephalexin & $\begin{array}{l}V+C \\
+A m\end{array}$ & - & $L P$ & 6 & Unfavorable \\
\hline 5 & 4 & $\mathrm{~F}$ & Trauma & 3 & $\mathrm{HM}$ & $\begin{array}{l}C T R+P P L+ \\
P P V+I O A B\end{array}$ & Nil & GPB & Ciprofloxacin & $V+C$ & - & $L P$ & 3 & Unfavorable \\
\hline 6 & 60 & M & $\begin{array}{c}\text { Postcataract } \\
\text { surgery }\end{array}$ & 6 & $L P$ & $P P V+I O A B$ & Nil & GPC & Ciprofloxacin & $V+C$ & - & $L P$ & 6 & Unfavorable \\
\hline 7 & 16 & $\mathrm{~F}$ & Endogenous & 20 & $L P$ & $P P V+I O A B$ & Enucleation & GPC & Ciprofloxacin & $V+A$ & - & NLP & 6 & Unfavorable \\
\hline
\end{tabular}

C, ceftazidime; T, triamcinolone; D, dexamethasone; V, vancomycin; A, amikacin; M, membranectomy; GPC, Gram-positive cocci; GPB, Gram-positive bacilli; CTR, corneal tear repair; PPV, pars plana vitrectomy; IOAB, intraocular antibiotic; PPL, pars plana lensectomy; Am, amphotericin $B$; $C F$, counting fingers; $L P$, light perception; NLP, no light perception; V/A, visual acuity. 
Table 2 Antimicrobial susceptibility of vancomycin-resistant Gram-positive organisms

\begin{tabular}{|c|c|c|c|c|c|c|c|c|c|c|}
\hline Number & Bacteria & Cefa & Cefta & $\mathrm{Ch}$ & Gen & Cipro & Gati & Oflox & Vanco & Amika \\
\hline 1 & Bacillus macerans & $\mathrm{R}$ & $S$ & $\mathrm{R}$ & $S$ & $S$ & $R$ & $\mathrm{R}$ & $R$ & $S$ \\
\hline 2 & Staphylococcus epidermidis & $\mathrm{R}$ & R & $\mathrm{R}$ & $\mathrm{R}$ & $S$ & $S$ & S & R & S \\
\hline 3 & Bacillus species & $\mathrm{R}$ & S & $\mathrm{R}$ & S & S & S & S & $\mathrm{R}$ & S \\
\hline 4 & Bacillus cereus & $\mathrm{R}$ & $\mathrm{R}$ & $\mathrm{R}$ & S & S & $\mathrm{R}$ & $\mathrm{R}$ & । & $\mathrm{R}$ \\
\hline 5 & Bacillus species & S & S & S & S & $S$ & $S$ & S & $\mathrm{R}$ & S \\
\hline 6 & Enterococcus faecalis & $\mathrm{R}$ & $\mathrm{R}$ & $\mathrm{R}$ & $\mathrm{R}$ & $\mathrm{R}$ & $\mathrm{R}$ & $\mathrm{R}$ & । & $\mathrm{R}$ \\
\hline 7 & Staphylococcus aureus & S & S & $\mathrm{R}$ & $\mathrm{R}$ & $S$ & $S$ & $\mathrm{R}$ & 1 & $\mathrm{R}$ \\
\hline
\end{tabular}

Amika, amikacin; Cefa, cefazolin; Cefta, ceftazidime; Ch, chloramphenicol; Gen, gentamicin; Cipro, ciprofloxacin; Gati, gatifloxacin; Oflox, ofloxacin; Vanco, vancomycin; $S$, sensitive; $R$, resistant; I, intermediate.

Gram-positive bacteria. In the present series, Bacillus sp. was the most common Gram-positive bacteria resistant to vancomycin. In a previous report, resistance among Bacillus sp. to vancomycin was noted in 10 of 31 (32.3\%) organisms isolated between 1991 and 1998 [8]. In another large case series reported by Miller and associates, all of the Bacillus sp. isolates were sensitive to vancomycin [9].

In the current study, most of the patients had poor visual outcomes. This can be attributed to multiple factors including initial delay in presentation, microbial resistance, and virulence of the organism, as well as concurrent trauma in some patients. It was interesting to note that these vancomycin-resistant Gram-positive organisms were most likely to be sensitive to the second-generation fluoroquinolone ciprofloxacin.

Quinupristin-dalfopristin, linezolid, daptomycin, and tigecycline have been used to treat systemic infections caused by vancomycin-resistant bacteria, though there are no formal recommendations for treatment of such endophthalmitis cases, given the paucity of these infections. Quinupristin/dalfopristin is a synthetic, parenteral, streptogramin antibiotic that acts by sequential ribosomal binding to inhibit protein synthesis and is effective in vitro against Enterococcus faecium, MRSA, Streptococcus pneumoniae, and other Gram-positive cocci. HernandezDa Mota reported successful treatment of endophthalmitis due to vancomycin-resistant $S$. aureus by administration of intravitreal $0.4 \mathrm{mg} / 0.1 \mathrm{ml}$ quinupristin/dalfopristin injection [10]. Linezolid is an oxazolidinone antibiotic that inhibits protein synthesis by binding to domain $\mathrm{V}$ of the 235 ribosomal RNA of the 50S subunit of bacterial ribosomes and is active in vitro against vancomycin-resistant Enterococcus, MRSA, vancomycin-resistant S. aureus, and penicillin-resistant S. pneumoniae. Systemic linezolid has been reported in the successful treatment of vancomycinresistant E. faecium endophthalmitis following penetrating keratoplasty [11]. Daptomycin is a lipopeptide that binds to the bacterial cytoplasmic membrane to effect release of intracellular ions and cell death. It demonstrates good in vitro bactericidal activity for vancomycin-resistant strains of bacteria accounting for endophthalmitis, including S. epidermidis, S. aureus, S. pneumoniae, E. faecalis, and E. faecium [12]. Comer and colleagues demonstrated that administration of $200 \mu \mathrm{g}$ of intravitreal daptomycin was safe and efficacious in a rabbit model of bacterial endophthalmitis [13]. Tigecycline is a glycylcycline antibiotic that binds to the $30 \mathrm{~S}$ ribosomal subunit to inhibit protein synthesis. It is active in vitro against MRSA, other multidrug-resistant Gram-positive cocci, and many Gramnegative bacilli [14].

Limitations of this report include the fact that the isolates were vancomycin-resistant by disk diffusion method which was not confirmed by MIC and the small number of cases in this retrospective series. However, it should be noted that these vancomycin-resistant organisms have been reported to be resistant to multiple other antibiotics [15]. In the current series, six of the seven isolates showed multidrug resistance.

\section{Conclusions}

In conclusion, vancomycin resistance among Gram-positive isolates is an uncommon but an emerging problem. The magnitude of antibiotic resistance requires ongoing surveillance and periodic reporting from individual laboratories.

\section{Competing interests}

The authors declare that they have no competing interests.

\section{Authors' contributions}

MK and AJ carried out the data collection and data analysis and drafted the manuscript. AP is one of the treating physicians and also carried out the correction of the manuscript. SJ, AM, RRP, NR, and TD are the other treating physicians. SS is the microbiologist. HWFJ corrected the manuscript. All authors read and approved the final manuscript.

\section{Author details}

${ }^{1}$ LV Prasad Eye Institute, GMR Varalakshmi Campus, Visakhapatnam 530040, India. 2Srimati Kanuri Santhamma Centre for Vitreoretinal Diseases, LVPEI, KAR Campus, Hyderabad 500034, India. 'LVEl, Bhubaneswar Campus, Bhubaneswar, Odisha 751024, India. ${ }^{4}$ Bascom Palmer Eye Institute, Department of Ophthalmology, University of Miami Miller School of Medicine, Miami, FL 33136, USA. 


\section{References}

1. Pathengay A, Moreker MR, Puthussery R, Ambatipudi S, Jalali S, Majji $A B$, Mathai A, Husssain N, Dave V, Sharma S, Das T (2011) Clinical and microbiological review of culture proven endophthalmitis caused by multidrug resistant bacteria in patients seen at tertiary eye care center in southern India. Retina 31:1806-1811

2. Das MK, Pathengay A, Shah GY, Koday NK (2011) Vancomycin-resistant coagulase negative Staphylococcus endophthalmitis following cataract surgery. J Cataract Refract Surg 37:1908-1909

3. Endophthalmitis Vitrectomy Study Group (1995) Results of the Endophthalmitis Vitrectomy Study. A randomized trial of immediate vitrectomy and of intravenous antibiotics for the treatment of postoperative bacterial endophthalmitis. Arch Ophthalmol 113:1479-1496

4. Bisicchia P, Bui NK, Aldridge C, Vollmer W, Devine KM (2011) Acquisition of VanB-type vancomycin resistance by Bacillus subtilis: the impact on gene expression, cell wall composition and morphology. Mol Microbiol 81:157-178

5. Han DP, Wisniewski SR, Wilson LA, Barza M, Vine AK, Doft BH, Kelsey SF (1996) Spectrum and susceptibilities of microbiologic isolates in the Endophthalmitis Vitrectomy Study. Am J Ophthalmol 122:1-17

6. Anijeet DR, Palimar P, Peckar CO (2010) Intracameral vancomycin following cataract surgery: an eleven-year study. Clin Ophthalmol 26:321-326

7. Sobaci G, Tuncer K, Taş A, Ozyurt M, Bayer A, Kutlu U (2003) The effect of intraoperative antibiotics in irrigating solutions on aqueous humor contamination and endophthalmitis after phacoemulsification surgery. Eur J Ophthalmol 13:773-778

8. Das T, Choudhury K, Sharma S, Jalali S, Nuthethi R (2001) Clinical profile and outcome in Bacillus endophthalmitis. Ophthalmology 108:1819-1825

9. Miller JJ, Scott IU, Flynn HW Jr, Smiddy WE, Murray TG, Berrocal A, Miller D (2008) Endophthalmitis caused by Bacillus species. Am J Ophthalmol 145:883-888

10. Hernandez-Da Mota SE (2011) Quinupristin/dalfopristin in Staphylococcus aureus endophthalmitis: a case report. J Med Case Reports 5:130

11. Bains HS, Weinberg DV, Feder RS, Noskin GA (2007) Postoperative vancomycin-resistant Enterococcus faecium endophthalmitis. Arch Ophthalmol 125:1292-1293

12. Rybak MJ, Hershberger E, Moldovan T, Grucz RG (2000) In vitro activities of daptomycin, vancomycin, linezolid, and quinupristin-dalfopristin against staphylococci and enterococci, including vancomycin-intermediate and resistant strains. Antimicrob Agents Chemother 44:1062-1066

13. Comer GM, Miller JB, Schneider EW, Khan NW, Reed DM, Elner VM, Zacks DN (2011) Intravitreal daptomycin: a safety and efficacy study. Retina 31:1199-1206

14. Noskin GA (2005) Tigecycline: a new glycylcycline for treatment of serious infections. Clin Infect Dis 2005:S303-S314

15. Srinivasan A, Dick JD, Perl TM (2002) Vancomycin resistance in staphylococci. Clin Microbiol Rev 15:430-438

doi:10.1186/1869-5760-3-46

Cite this article as: Khera et al.: Vancomycin-resistant Gram-positive bacterial endophthalmitis: epidemiology, treatment options, and outcomes. Journal of Ophthalmic Inflammation and Infection 2013 3:46.

\section{Submit your manuscript to a SpringerOpen ${ }^{\circ}$ journal and benefit from:}

- Convenient online submission

- Rigorous peer review

- Immediate publication on acceptance

- Open access: articles freely available online

- High visibility within the field

- Retaining the copyright to your article

Submit your next manuscript at $\gg$ springeropen.com 